\title{
Nilai-Nilai Edukatif Dalam Tradisi Ujung: Kajian Etnografi Di Masyarat Boyolali Jawa Tengah
}

\author{
Sigit Haryanto(1) \\ sh288@ums.ac.id
}

DOI: 10.23917/varidika.v32i1.10673

\begin{tabular}{|c|c|}
\hline Submission & ABSTRACT \\
\hline Track: & \\
\hline Received: & $\begin{array}{l}\text { Cultural values always exist in the physical form of tradition. One of the } \\
\text { traditions that have rich of values is ujung tradition. It is annual event }\end{array}$ \\
\hline 10 Febuary 2020 & held by most Javanese people. It has a correlation to lebaran fitr. The \\
\hline Final Revision: & $\begin{array}{l}\text { participants of this tradition are from children to old people. Visiting } \\
\text { their parent, relative, and neighbor are compulsory activity. In addition }\end{array}$ \\
\hline 10 March 2020 & $\begin{array}{l}\text { to, they also utter forgiveness each other. The objective of this study is } \\
\text { finding the values behind ujung tradition viewed from educative point. }\end{array}$ \\
\hline Available online: & $\begin{array}{l}\text { Ethnographic study was selected to conduct the research and } \\
\text { participant observation was used to collect the data. Then the data were }\end{array}$ \\
\hline 31 June 2020 & analyzed by using component analysis proposed by Spradlay. The results \\
\hline Corresponding & $\begin{array}{l}\text { of the study showed that there five educative values inside the ujung } \\
\text { tradition, namely: respect, togetherness, advice, pray, and charity. From }\end{array}$ \\
\hline Author: & $\begin{array}{l}\text { this it is understood that ujung tradition is still run well in society due } \\
\text { to many educative values that ought to be transferred. }\end{array}$ \\
\hline Sigit Haryanto(1) & Keywords: ujung tradition, cultural values, javanese society \\
\hline Sh288@ums.ac.id & \\
\hline
\end{tabular}




\section{PENDAHULUAN}

Tradisi sebagai wadah hasil pemikiran manusia berisikan banyak hal. Salah satunya adalah pewarisan nilai-nilai kehidupan (Rachman, 2012). Nilai-nilai luhur tersebut berawal dan berasal dari nilai-nilai luhur yang disepakati oleh rakyat penduduk wilayah tertentu, kemudian meluas dan disepakati oleh masyarakat (Ningsih, 2019). Pewarisan terkait erat dengan mind of the culture yang normalnya bermuatan ajaran untuk menjadikan hidup yang harmonis. Ajaran luhur akan sampai kepada pewaris bilamana ada wadah dan kegiatan yang dijalankan secara berulang-ulang. Berulangnya kegiatan bisa harian, bulanan, atau tahunan. Kegiatan atau aktiftas yang berulang inilah yang dinamakan tradisi. Tradisi terkait dengan segala bentuk warisan masa lampau, hingga berjalan sampai menuju zaman saat ini dan menjadi bagian dari kebudayaan yang sekarang berlaku (Ridho, 2019).

Terkait dengan tradisi, masyarakat Jawa kaya akan hal itu, baik yang berhubungan dengan Islam maupun yang tidak. Salah satu tradisi yang erat hubungannya dengan kegiatan masyarat Islam adalah tradisi ujung. Tradisi ini sudah berjalan puluhan tahun yang lalu. Sebelum penulis lahir kegiatan ini sudah ada atau bahkan sebelum Indonesia merdeka. Menurut KH Abdul Wahab Chasbullah tradisi ini secara substansi telah ada sejak zaman Pangeran Sambernyawa pada abad ke-18. Kala itu dengan istlah sungkeman. Sebab, pada masa itu, Idul Fitri dirayakan dengan pertemuan antar prajurit dengan raja di balai istana. Setiap prajurit secara tertib melakukan sungkem atau meminta dukungan dari para raja dan permaisuri (Husna, 2019).

Dalam kehidupan masyarakat Jawa, kata sungkeman, halal bi halal, dan ujung memiliki kesamaan maksud. Akan tetapi sebenarnya memiliki perbedaan suasana. Sungkeman terkait dengan bakti pada orang tua atau orang yang lebih tua dengan tuturan permohonan maaf atau doa dan tidak terikat waktu. Halal bi halal adalah peristiwa bakti pada orang tua yang terkait dengan maaf memaafkan dan terikat waktu. Adapun ujung sebenarnya tidak jauh dari halal bi halal, akan tetapi memiliki karakteristik sendiri. Sungkeman bisa terjadi di acara manten dan bisa juga tidak, sedangkan halal bi halal dan ujung terjadi setelah hari raya idul fitri. Tidak ada acara halal bi halal dan ujung dilakukan pada acara mantenan atau sebelum lebaran fitri. Ujung dan halal bi halalpun juga berbeda. Di kantor-kantor ataupun di rt-rt acara maaf memaafkan menggunakan istilah halal bi halal, tidak menggunakan istilah ujung. Yang sering kita jumpai adalah 'acara halal bi halal dan sillaturahim ..., bukan acara 'ujung dan silaturahim'.... Namun kadang kita juga menjumpai istilah sungkeman dan halal bi halal yang disamakan dengan ujung, 
akan tetapi yang popular di masyarat Jawa, khususnya Boyolali dan sekitarnya adalah kata ujung. Akan tetapi istilah tersebut, walaupun ada dan dijalankan dengan baik, sampai saat ini belum ada kajian ilmiahnya. Kalau kajian halal bi halal sudah ada, contohnya: Halalbihalal Dalam Perspektif Adat Dan Syariat, Maisarotil Husna, STAIN Sultan Abdurrahman Kepulauan Riau dalam jurnal Perada: Jurnal Studi Islam Kawasan Melayu. Selanjutnya, gambaran ujung yang ada di masyarat Jawa, khususnya di Boyolali dikemukakan dalam contoh satu berikut.

Contoh 1: Setting dan bahasa ujung antara cucu dengan nenek

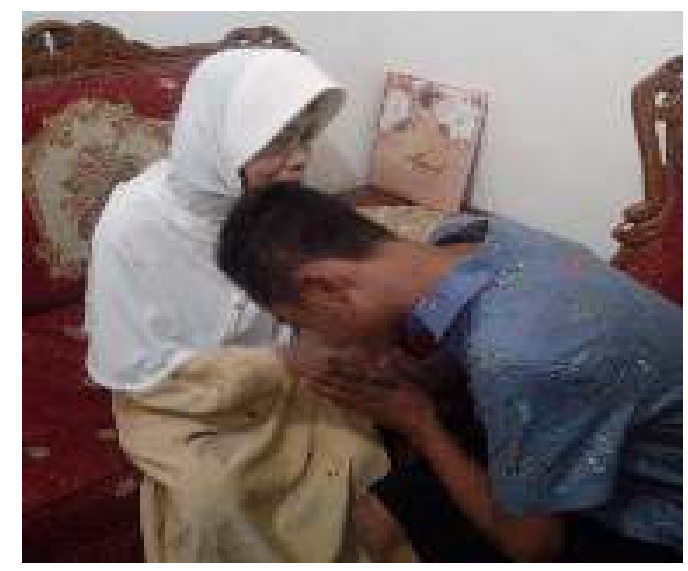

Gambar 1. Ilustrasi Bahasa Ujung Antara Cucu dengan Nenek

Cucu: Mbah ngaturaken sugeng riyadin, sedaya kalepatan nyuwun ngapunten.

'Nenek, mengucapkan selamat hari raya, semua kesalahanku mohon dimaafkan'.

Nenek: Ya le, sepira luputku aku njaluk ngapura, dosaku lan dosamu muga-muga lebur ana ing dina bakda iki, dongaku wae marang kowe muga-muga sekolahmu lancar, lan sing bekti marang wong tuwa'.

'Ya mas seberapa kesalahan saya, saya minta maaf, dosa saya dan dosa kamu semoga hapus di hari raya ini, doa saya pada mu semoga sekolahmu lancar dan yang berbakti kepada kedua orang tuamu'.

Setting dan bahasa yang tertera di contoh 1 merupakan aktivitas budaya yang di dalamnya ada ungkapan verbal dan nonverbal. Di dalamnya banyak mengandung nilai-nilai edukatif, yakni nilai-nilai yang dapat menuntun tiap individu ketika berperilaku dalam 
kehidupan bermasyarakat (Husna, 2019). Nilai-nilai edukatif dipraktikkan cucu merupakan ajaran orang tua.Sekilas nilai yang ada di contoh 1 adalah nilai hormat yang tercermin dari cara duduk dan bicara. Cucu duduk dengan lebih rendah dan tidak memandang nenek menunjukkan adab hormat pada orang tua. Di samping itu juga cucu menggunakan bahasa Jawa dengan tingkat tutur krama menjadi barometer hormat pada orang tua. Tradisi ujung tidaklah berisi nilai-nilai edukatif semacam itu saja, akan tetapi tentunya masih banyak yang lain.

Ujung adalah tradisi. Tradisi merupakan pasangan dari adat. Adat dan tradisi (custom and tradition) bagian dari budaya. Salah satu ahli budaya merumuskan bahwa budaya memiliki tujuh unsur (Carr, 2015). Adapun salah satu unsurnya adalah adat dan tradisi (lihat gambar 1).

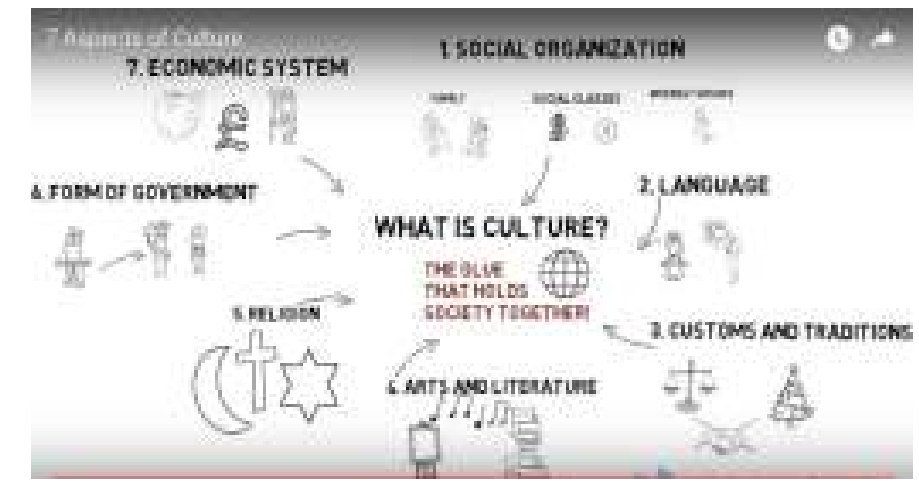

Gambar 2 Tujuh elemen Budaya. Sumber: Rebecca Carr

Adat dan tradisi merupakan media menyatukan masyarakat (the glue that holds society together). Pemikiran semacam itu tercermin pada tujuh unsur budaya. Tradisi ujung yang dicetuskan oleh pendahulu kita tentunya berisikan sesuatu yang mengarah pada bagaimana masyarakat itu rukun dan damai. Pemikiran atau ajaran tersebut diterima oleh masyarakat dan selanjutnya dilestarikan dengan diulang-ulangnya kegiatan tersebut. Anak cucu mereka diajak dan diajari memahami dan mempraktikkan ajaran dari leluhurnya. Nilai-nilai kebaikan yang ada di dalamnya diyakini dapat menyatukan mereka dalam kedamaian. Bukankah nilai itu terkait dengan sifat-sifat (hal-hal) yang penting atau berguna bagi kemanusiaan dan bisa juga konsep abstrak mengenai masalah dasar yang sangat penting dan bernilai dalam kehidupan manusia (Bahasa, 2016).

Tradisi ujung tentunya berisikan kebaikan-kebaikan. Sebagai bukti tiap tahun dari dulu sampai sekarang masih dijalankan dengan baik. Masyarakat meyakini bahwa banyak kandungan positif 
atau nilai edukatif di dalamnya yang wajib diberikan pada keturunanya. Kandungan positif atau nilai edukatif apa sajakah yang ada dalam tradisi ujung yang perlu digali dan disebarluaskan menjadi fokus tulisan ini.

\section{METODE PENELITIAN}

Metode Penelitian berisi deskripsi tempat dan waktu penelitian, jenis penelitian, data dan sumber data penelitian, teknik pengumpulan data, validitas data, analisis data, penyajian hasil analisis data, dan perpaduan metode etnografi dan metode linguistik. Secara deskriptif uraian lengkapnya seperti berikut.Tempat penelitian di Cepogo Boyolali. Waktu penelitian pada bulan Juni 2018. Jenis Penelitian kualitatif sehingga penelitian ini lebih menekankan pada masalah proses dan makna (Sutopo, 2006). Artinya, analisis dan interpretasi hasil penelitian sudah dilakukan sejak bersamaan dengan pengumpulan data tentang tanda kebahasaan yang digunakan, pelaku, situasi dan makna yang ada di dalam tradisi ujung. Kajiannya berbentuk kualitatif dalam bentuk kata-kata dan bukan angka-angka matematis dan statistik. Bertitik tolak dari lokasi penelitian yang telah ditentukan, maka penelitian ini termasuk penelitian terpancang (embedded research). Informasi yang dibutuhkan mencakup tiga hal, yakni (1) informasi tanda kebahasaan, (2) pelaku dan situasi, dan (3) nilai-nilai edukatitfyanga ada. Data penelitian ini adalah peristiwa dan tuturan lisan yang berupa kata, frasa, dan kalimat. Sumber data penelitian ini adalah informan terpilih yang memahami budaya ujung. Teknik pengumpulan data menggunakan observasi partisipasi (participant observation) dan wawancara. Validitas data penelitian kualitatif ini dengan teknik triangulasi (triangulation), reviu informan kunci (key informant review) dan member check. Analisis data penelitian dilakukan dengan teknik analisis komponen yang dikemukakan oleh Spradley, yakni analisis domain terkait dengan peristiwa pra ujung, saat ujung dan pasca ujung. Kemudian dilanjutkan dengan analisis taksonomi, yang meliputi: peristiwa peristiwa yang ada pada masing-masing domain. Hasil analisis data disajikan dengan teknik informal dan formal. Teknik informal adalah penyajian dengan katakata biasa, sedangkan teknik formal adalah penyajian dengan menghadirkan tanda-tanda atau lambang-lambang (Sudaryanto, 2015). Hasil analisis agar bisa dipahami oleh pembaca akan disajikan secara berbarengan sesuai dengan konteks penyajian, uraian kalimat dulu kemudian lambang atau tanda, atau sebaliknya tanda/lambang baru diikuti uraian kalimat. 


\section{HASIL DAN PEMBAHASAN}

Hasil penelitian disajikan dalam tiga tahap. Pertama, penyajian yang terkait dengan nilai-nilai edukatif yang ada pada kegiatan sebelum prosesi ujung. Kedua, penyajian pada saat prosesi. Ketiga, penyajian hasil yang terkait dengan sesudah acara ujung.

\section{Nilai-nilai edukatif sebelum acara ujung}

\section{a. Nilai sedekah}

Amal adalah perbuatan. Berbuat baik pada orang lain termasuk nilai luhur dalam kehidupan. Beramal baik itu sama dengan bersedekah. Ajaran ini dipraktikkan oleh masyarakat Boyolali dalam berbagai even. Terkait dengan beramal menjelang acara inti ujung, mereka biasanya membawa makanan ke suatu titik kumpul yang kemudian diadakan doa bersama dan setalah itu makanan yang mereka bawa dibagikan (lihat gambar 2).

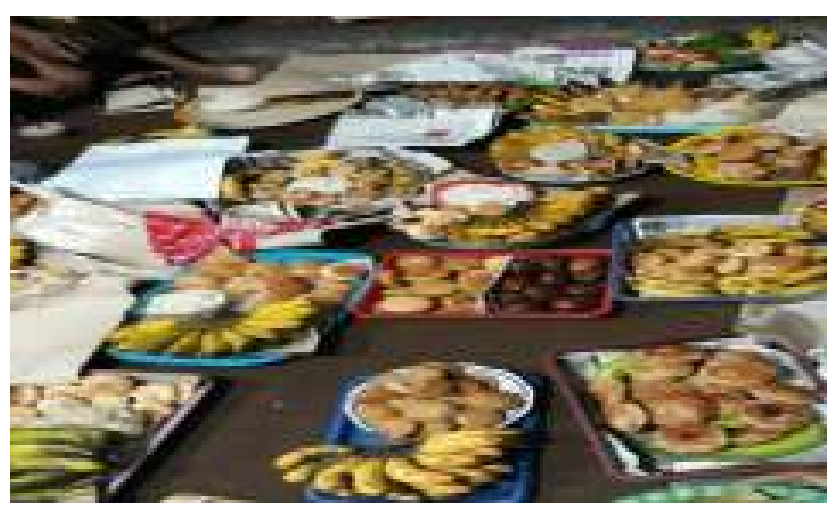

Gambar 3 barang sedekah

\section{b. Nilai hormat}

Masyarat Boyolali biasanya menyambut lebaran fitri dengan melakukan berbagai kegiatan. Misalnya, mereka menghias rumah, mengecat ulang rumah, membeli perabot rumah baru, dan menata ruangan. Di samping itu juga mereka menyiapkan berbagai macam makanan, baik makanan besar maupun kecil. Kupat, lontong, opor ayam, dan rendang sapi disiapkan untuk tamu yang akan datang.Makanan kecil seperti kacang goreng, mete, emping minjo, roti, premen, dan seturusnya juga dipersiapkan dengan baik (lihat gambar 3). 


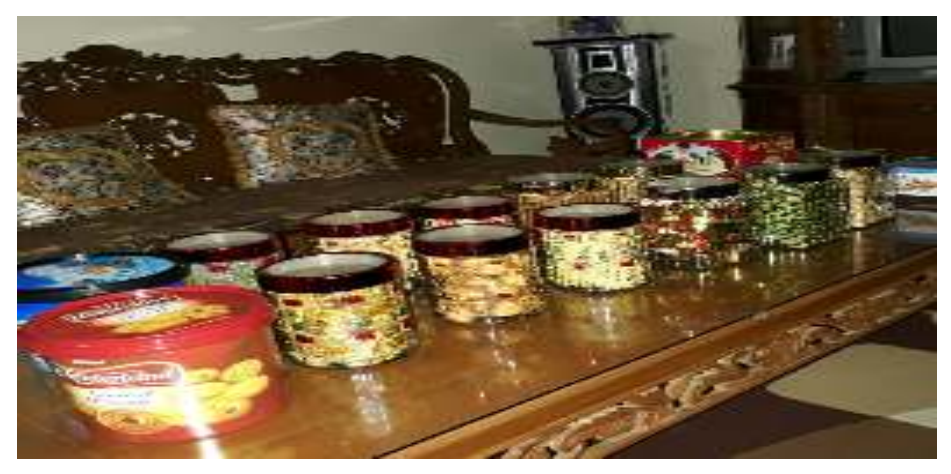

Gambar 4 Macam-macam makanan kecil hari raya Fitri

Makanan dipersiapkan guna menyambut tamu yang akan datang. Masyarakat Boyolali tidak berhitung untung dan rugi. Persiapan makanan besar dan kecil bisa menelan biaya jutaan rupiah. Mereka dengan senang dan iklas mempersiapkan semuanya. Mereka punya prinsip tamu itu harus dihargai atau dihormati karena dampak dari perbuatan itu akan kembali kepada diri mereka.

\section{Nilai-nilai edukatif saat acara ujung}

\section{a. Nilai silaturahim}

Menyambung tali persaudaraan menjadi bagian penting dalam kehidupan bermasyarakat. Cara yang ditempuh tentunya beraneka ragam, misalnya reuni, menghadiri acara perkawinan, dan menjalankan tradisi ujung. Berkunjung ke rumah orang tua, saudara, atau tetangga adalah media menjalin dan mempererat hubungan kekeluargaan. Para pelaku ujung menjalankan kegiatan itu mulai dari setelah salat idhul fitri sampai hari keempat atau kelima. Kepala rumah tangga mengajak istri dan anakanaknya bersilaturahim ke rumah kakek/nenek, saudara, dan tetangganya (lihat gambar

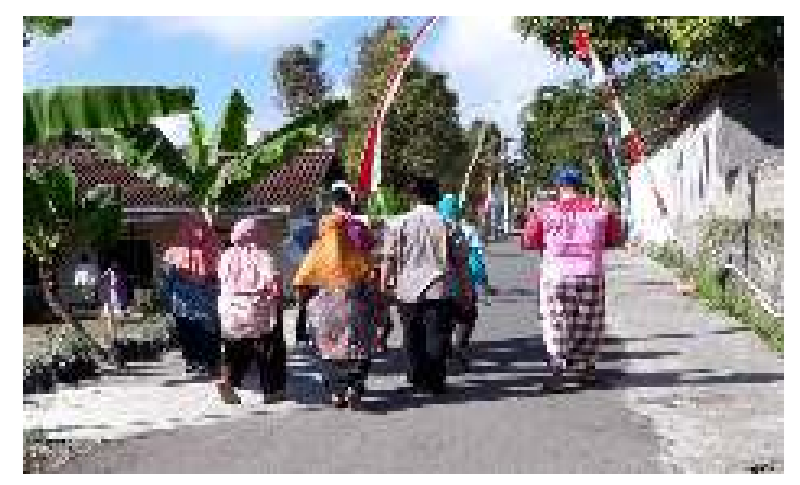

Gambar 5 Bersama menuju rumah tetaangga dan saudara 


\section{b. Nilai hormat}

Pada acara inti, kegiatan yang dilakukan adalah mengucapkan kata saling permohonan maaf dengan menggunakan wacana dialogis. Biasanya dan umumnya orang pertama yang memulai dialog dengan isi tuturan ucapan salam hari raya idul fitri dan permohonan maaf, namun juga ada variasi ujaran yang lain. Akan tetapi dua hal tersebut yang sering muncul. Setelah orang pertama tersebut selesai bertutur, selanjutnya orang kedua menjawab tuturan orang pertema tersebut. Tuturan orang kedua berisi permohonan maaf, nasehat, dan doa.

Nilai hormat terlihat dari pemakian kode krama kepada orang kedua dan hampir diseluruh data demikian. Akan tetapi orang kedua umumnya memilih kode ngoko dalam menjawab, namun ada beberapa data yang menunjukkan bahwa orang kedua menggunakan kode krama kepada orang pertama. Mereka berturur dengan kode krama kepada orang pertama karena orang pertama memiliki status sosial tinggi dan orang yang belum dikenal.

Wujud hormat orang pertama kepada orang kedua berikutnya terlihat dari aktivitas nonverbal, yakni cara duduk, cara memegang tangan, dan cara menatap wajah. Orang pertama biasanya cara duduknya lebih bawah atau mengambil posisi lebih rendah. Cara memegang tangan dengan tangan dua yang erat, sedangkan wajahnya merunduk, tidak menatap langsung. Bahasa dan potret aktivitas nonverbal mereka seperti terlihat dalam dialog satu dan gambar 4.

Dialog satu:

Orang pertama: Mbah sepisan ngaturaken sugeng riyadin,kaping kalih sedaya kalepatan kula ingkang kula sengaja utawi mboteh kula sengaja mugi panjenengan paringi pangapunten.

'Eyang pertama mengucapkan selamat hari raya, kedua, semua kesalahanku yang saya sengaja maupun tidak mohon dimaafkan'. 
Orang kedua:Ya mas, sepira luputku aku uga njaluk ngapura, dosaku lan dosamu muga-muga lebur ana ing dina bakda iki, dongaku wae marang kowe sing rukun anggonmu bebrayan, sing sabar momong anak bojomu, tambah bekti marang pangeran.

'Ya mas, seberapa kesalahan saya, saya juga minta maaf, dosa saya dan dosa kamu semoga hapus di hari raya ini, doa saya pada mu, yang rukun dalam berumah tangga, yang sabar mengasuh anak dan istri, semakin dekat dengan Tuhan'.

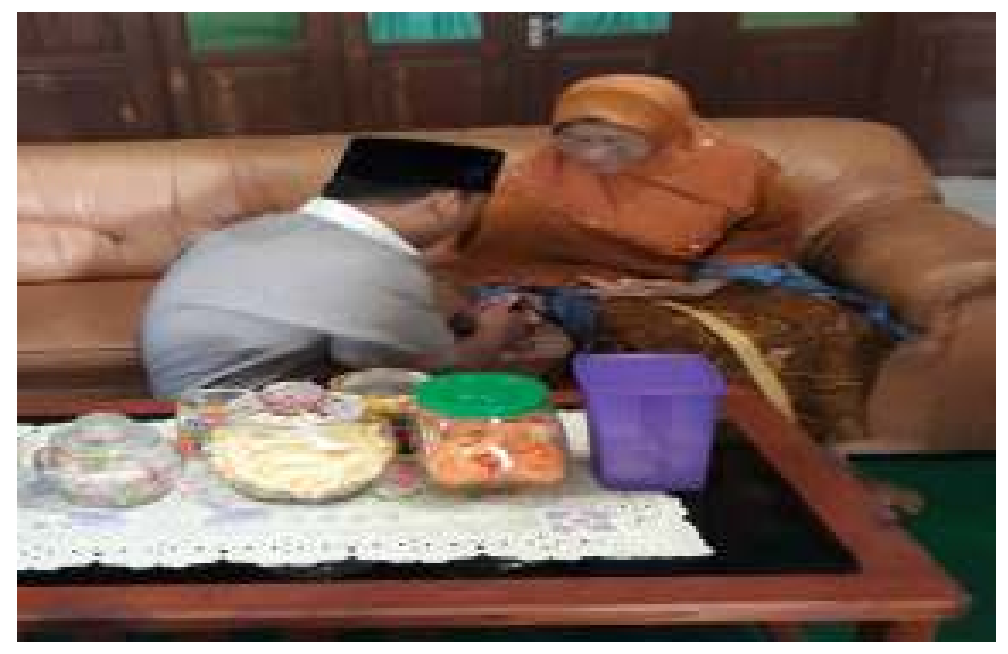

Gambar 6 aktivitas nonverbal pada saat ujung

\section{c. Nilai nasehat}

Nasehat menasehati adalah bagian dari perilaku baik. hal ini juga dipraktikan oleh masyrakat Jawa dalam tradisi ujung. Wujud nasehat tercermin dalam ujaran orang kedua berikut: sing bekti marang wong tuwa 'yang berbakti kepada kedua orang tuamu', sing sregep ngibadahe ' yang rajin ibadahnya', kowe sekolah seng pinter ben ndang dadi guru ' kamu sekolahnya yang rajin biar jadi guru'. Perlu diketahui bahwa menasehati 
itu menjadi ranahnya orang kedua yang umumnya lebih tua. Tidak ada orang pertama itu menasehati.

\section{d. Nilai doa}

Mendoakan adalah juga menjadi nilai edukatif yang ada dalam tradisi ujung. Yang banyak mendoakan adalah orang kedua. Orang pertama biasanya minta didoakan. Contoh ujaran mendoakan seperti berikut: tak dongake muga-muga kasembadan apa sing dadi panjalukmu 'saya doakan semoga tercapai apa yang menjadi permintaanmu'; muga-muga sekolahmu lancar 'semoga sekolahmu sukses'; tak dongakke cedak jodone 'saya doakan dekat jodohnya.

\section{Nilai-nilai edukatif setelah acara ujung}

\section{a. Nilai sedekah}

Kegiatan setelah acara utama selesai adalah pemberian uang kepada anak-anak. Besarnya uang variatif, tergantung kondisi pemberi dan yang diberi. Pemberi tergolong kaya akan member uang lebih besar, dan yang diberi anak kecil akan berbeda dengan anak remaja. Kegiatan memberi uang setelah acara ujung dinamakan bagi-bagi firah atau memberi fitrah (lihat gambar 6).

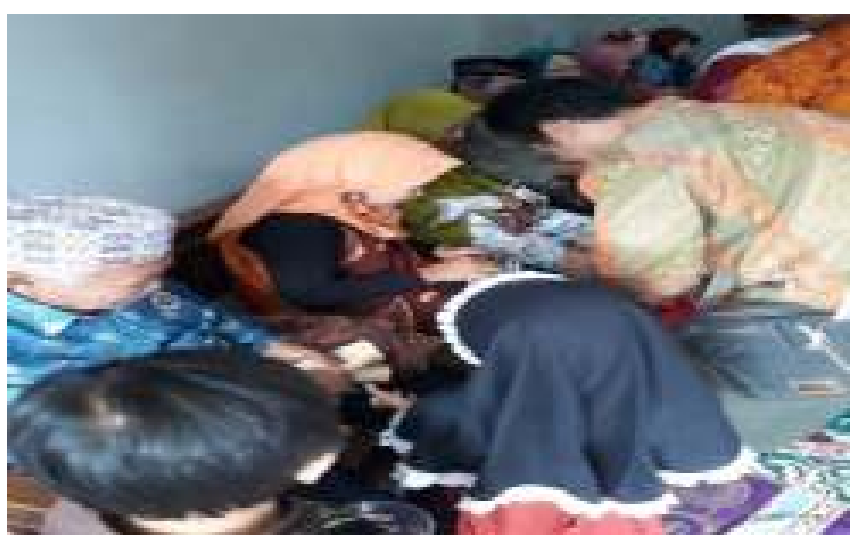

Gambar 7 Suasana pembagian fitrah 


\section{Pembahasan}

Esensi tradisi ujung dekat sekali dengan filisofi masyarakat Jawa berikut: tutur, sembur, dan wuwur. Turur itu menuturi atau memberi nasehat. Sembur adalah doa yang dipanjatkan. Adapun wuwur itu weweh, memberi. Dalam norma Jawa, yang menuturi atau menasehati adalah orang tua atau orang yang lebih tua sehingga dalam komunikasi dialogis ini peran orang kedualah yang dominan. Wujud tuturan tergantung lawan bicara atau bersifat kontekstual. Yang dinasehati anak kecil isinya disuruh berbakti kepada orang tua, belajar yang rajin, salatnya yang rajin, dll. Kalau orang yang sudah berkeluarga dinasehati supaya sungguh-sungguh dalam mendidik anak, sayang dengan anak dan istri, dan hati-hati dalam hidup.

Sembur atau doa juga menjadi isi wacana ujung. Peran doa biasanya diambil oleh orang kedua. Mereka mendoakan agar orang pertama: menjadi orang pintar, terkabul permintaannya, rukun dan damai kehidupan rumah tangganya, jadi orang kaya, orang berpangkat, dan selalu diberi kesehatan (Sairin, 1982).

Wuwur atau memberi adalah termasuk ajaran kebaikan dalam rangka hablu minnannas, hubungan antar sesama manusia (Kamal, 2017). Banyak hal yang diajarkan dari wuwur ini, yakni: mengakrapkan persaudaran, menunjukkan kasih sayang, membantu orang lain, dll. Wuwur dalam tradisi ujung terlihat di pra dan sesudah acara resmi ujung. Sedekah makanan yang dibawa ke masjid atau tempat khusus adalah wujud wuwur sebelum acara inti ujung dan pembagian fitrah atau uang kepada anak, keponakan atau tetangga yang hadir adalah bentuk wuwur atau sedekah (Anwar, 2013).

Warisan budaya yang berupa nilai-nilai luhur ini menjadi nilai wajib yang harus diajarkan kepada anak cucu kita supaya hidup di lingkup keluarga inti, keluarga besar, maupun dalam masyarakat tidak ada konflik, saling menghargai, tepa salira, rukun, dan saling membantu. Keluarga dalam hal ini bapak dan ibu mengajarkan nilai-nilai kehidupan yang ada dalam kemasan budaya supaya berhasil dalam hidupnya di masyarakat. Terkait dengan tiga hal: keluarga, budaya dan masyarakat, (Geertz, 1961) mengemukakan pendapatnya sebagai berikut: 
"The family, in any society, is the bridge between the individual and his culture"......Two distinctively Javanese values have appeared often in the foregoing description of Javanese family life...... These are, first, the cluster of values involved in the Javanese view of the etiquette of "respect," and secondly, those concerned with the Javanese emphasis on the maintenance of "harmonious social appearances.

Keluarga adalah penghubung antara individu dengan makna-makna budaya yang telah disepakati dan berlaku di masyarakat. Makna-makna budaya yang termasuk kelompok besar yang dipegang teguh oleh masyarakat Jawa itu adalah makna respect atau hormat dan maintenance of "harmonious social appearances" atau rukun. Masih menurut dia: "the proper expression of "respect" (what the Javanese refer to as showing urmat or feeling sungkan) is based on the traditional Javanese view that all social relationships are hierarchically ordered, and on the moral imperative to maintain and express this mode of social order as a good in itself.

Hormat adalah perilaku menghargai orang-orang yang berada pada tataran yang lebih tinggi baik dari segi umur maupun kedudukan sosial. Terkait dengan rukun atau maintenance of "harmonious social appearances", dia memberi tambahan penjelasan sebagai berikut:

The second one (summed up in Javanese as rukun), the determination to maintenance of "harmonious social appearances", to minimize the overt expression of any kind of social and personal conflict, is based on the Javanese view that emotional equilibrium, emotional stasis, is of highest worth, and on corresponding more improve to control one's own impulses, to keep them out of awareness or at least unexpressed, so as not to set up reverberating emotional responses in others".

Makna rukun terkait dengan usaha menghindari terjadinya konflik terbuka antar individu. Menjaga emosi supaya tidak terjadi benturan batin selalu diupayakan dengan jalan diam atau meminimalisasi ungkapan.

Terkait dengan dua prinsip dasar orang Jawa, yakni hormat dan rukun, orang Jerman yang bernama (Magnis-Suseno, 2001) juga telah meneliti dan dituangkan dalam 
buku yang berjudul Etika Jawa. Dia dia menjelaskan bahwa ada duah kaidah yang paling nenentukan pola pergaulan dalam masyarakat Jawa. Kaidah pertama mengatakan bahwa dalam setiap situasi manusia hendaknya bersikap sedemikian rupa sehingga tidak sampai menimbulkan konflik. Kaidah kedua berbunyi agar manusia dalam cara bicara dan membawa diri selalu menunjukkan sikap hormat terhadap orang lain, sesuai dengan derajat dan kedudukannya. Kaidah pertama diberi nama prinsip rukun atau maintenance of "harmonious social appearances" Yang kedua diberi nama prinsip hormat atau respect. Dua prinsip ini merupakan kerangka normatif yang menentukan bentuk-bentuk konkrit semua interaksi dalam masyarakat Jawa.

Prinsip rukun diajarkan oleh orang tua sejak kecil, misalnya, le karo sedulur kuwi sing rukun (anakku, sesama saudara itu yang rukun), karo adikne sing ngalah (sama adiknya mengalah). Dua contoh itu memberi gambaran kepada kita bahwa masyarakat Jawa ingin kehidupan ini tidak terjadi perselisihan. Kehidupan yang tenang dan tenteram tanpa ada konflik antar anggota keluarga menjadi pegangan hidup mereka.

Tradisi ujung tentunya terkait erat dengan apa yang dikemukakan oleh Geertz dan Magnis Suseno. Dilihat dari yang ditemukan di pra ujung, saat ujung, dan pasca ujung terlihat bahwa apa yang dikemukakan oleh kedua tokoh budaya menjadi sentral ajaran yang wajib diberikaan kepada anak cucu mereka supaya tercapai esensi kehidupan, yakni saling menghormati dalam kerukunan.

\section{SIMPULAN}

Tradisi ujung menjadi bagian budaya Jawa yang sampai sekarang masih dilakukan dengan baik. Buktinya tiap tahun masyarakat Jawa menanti nanti datangnya mumen tersebut. Mereka menyiapkan segala sesuatunya untuk menyambut kedatangan anak, saudara, maupun tetangga. Persiapan biasanya sudah dimulai semenjak datangnya bulan puasa. Menghias rumah, membeli baju baru, dan menyiapkan hidangan dan keuangan adalah hal yang masuk dalam agenda mereka. Semua itu bertujuan agar bisa menghormati orang lain dan menjaga keharmonisan dan keselarasan hidup.

Dari sisi pewarisan nilai-nilai edukatif, sebenarnya secara tidak langsung anak cucu sudah diajari hal tersebut. Mereka dilibatkan dalam rangkaian kegiatan ujung baik dari pra, saat, 
dan pasca ujung sehingga pembelajaran nilai kebaikan seperti sedekah, hormat, minta maaf, dan silaturahim bisa menjadi bekal hidup yang bermanfaat bagi mereka.

\section{REFERENSI}

Anwar, K. (2013). Makna Kultural Dan Sosial-Ekonomi Tradisi Syawalan. Walisongo: Jurnal Penelitian Sosial Keagamaan, 21(2), 437. https://doi.org/10.21580/ws.2013.21.2.253

Bahasa, B. P. dan P. (2016). KBBI. https://kbbi.web.id/nilai

Carr, R. (2015). Senen element of culture. https://www.youtube.com/watch?v=u2a9OP3_U0

Geertz, H. (1961). The Javanese Family: A Study of Kinship and Socialization. The Free Press of Glencoe, Inc.: America.

Husna, M. (2019). Halal Bihalal Dalam Perspektif Adat Dan Syariat. Perada, 2(1), 45-56. https://doi.org/10.35961/perada.v2i1.29

Kamal, M. A. M. (2017). Interelasi Nilai Jawa dan Islam dalam Berbagai Aspek Kehidupan. Kalam, 10(1), 19. https://doi.org/10.24042/klm.v10i1.18

Magnis-Suseno, F. (2001). Etika Jawa. Gramedia Pustaka Utama.

Ningsih, T. (2019). Tradisi Saparan Dalam Budaya Masyarakat Jawa Di Lumajang Tutuk. Kajian Islam Dan BUdaya, 17, no 1, 79-93. https://doi.org/10.24090/IBDA.V17i1.1740

Rachman, M. (2012). Konservasi Nilai Dan Warisan Budaya. Indonesian Journal of Conservation, 1(1), 30-39.

Ridho, A. (2019). Tradisi Megengan Dalam Menyambut Ramadhan Living Qur ${ }^{\text {ee }}$ an Sebagai Kearifan Lokal Menyemai Islam di Jawa Ali. Literasiologi, 1(2), 62-63.

Sairin, S. (1982). Javanese Clan: Kin-Based Social Organization. Gadjah Mada University Press.

Sudaryanto. (2015). Metode dan Aneka Teknik Analisis Bahasa. Sanata Dharma University Press. (ed.).

Sutopo, H. B. (2006). Metodologi Penelitian Kualitatif: Dasar Teori dan Terapannya dalam Penelitian Ilmu-ilmu Sosial dan Budaya. Surakarta: Sebelas Maret University Press. 